\title{
Prenylamine-induced ventricular tachycardia and syncope controlled by ventricular pacing
}

\author{
E GRENADIER, S KEIDAR, G ALPAN, A MARMOR, A PALANT \\ From the Department of Cardiology, Lady Davis Carmel Hospital, Haifa, Israel
}

SUMMARY We describe eight patients treated for angina with prenylamine who developed lifethreatening ventricular arrhythmias after QT interval prolongation. When prenylamine administration was stopped QT interval shortened to within normal values, while the ventricular arrhythmias were controlled by a temporary ventricular pacemaker and disappeared after several days. We stress the importance of surveillance of the QT interval and ventricular arrhythmias in patients receiving long-term treatment with prenylamine.

Since its introduction as an antianginal agent, prenylamine has been shown to have a wide margin of therapeutic safety. ${ }^{1}$ Indeed very few lifethreatening complications of prenylamine treatment have been reported. ${ }^{2-5}$ Thus the association of ventricular arrhythmias with prenylamine is of some interest, especially in view of the fact that it can be anticipated and thus avoided.

We report on the mode of treatment of eight patients with prolonged QT intervals and serious symptomatic ventricular tachyarrhythmias caused by prenylamine.

\section{Patients and results}

The eight patients constituting this group were admitted to the Department of Cardiology at the Lady Davis Carmel Hospital because of several Received for publication 26 February 1980 episodes of syncope in the few weeks preceding admission.

They had coronary artery disease with mild anginal syndrome and were on a regimen of prenylamine 180 to $240 \mathrm{mg} /$ day for at least two months before being admitted to hospital. Clinical details and additional drugs are summarised in the Table.

On arrival all patients had electrocardiograms showing prolonged QT interval, ventricular premature beats, and short runs of ventricular tachycardia with torsade de pointes pattern (Fig. 1-4).

In the first four patients treatment with lignocaine was initiated immediately; this failed, however, to control the arrhythmia. Moreover, two patients (cases 1 and 3) developed transient Mobitz second and third degree atrioventricular block on being given a $100 \mathrm{mg}$ bolus of intravenous ligno-

Table Clinical, laboratory, and electrocardiographic data of patients on prenylamine with torsade de pointes

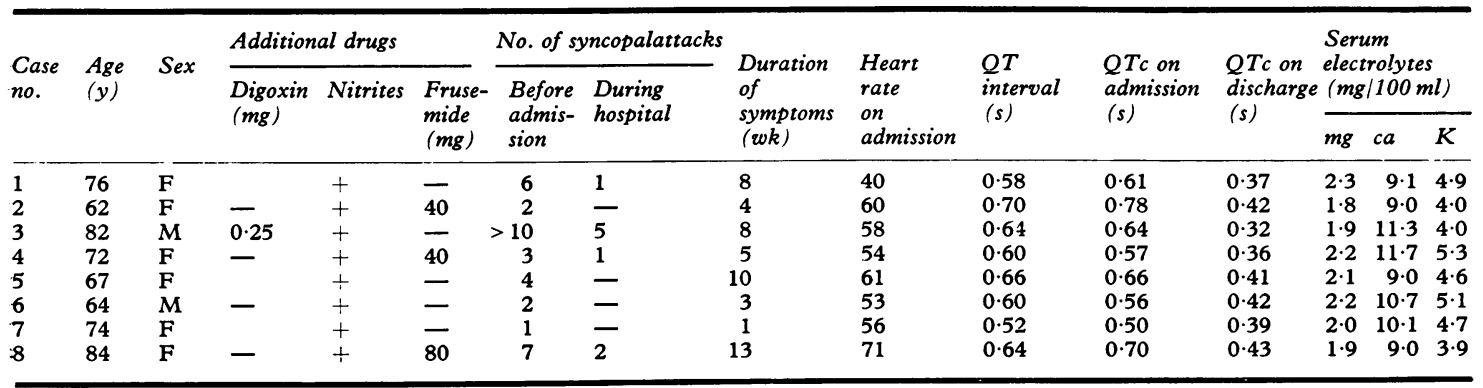

QTc was calculated according to the formula of Bazzet: $\mathrm{QTc}=\frac{\mathrm{QT}}{\sqrt{\mathrm{R}-\mathrm{R}}}$ 


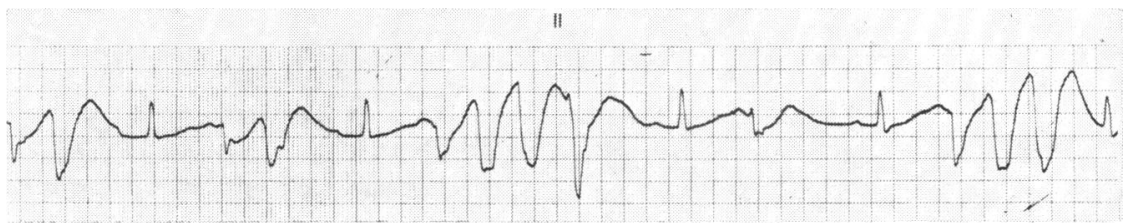

(a)

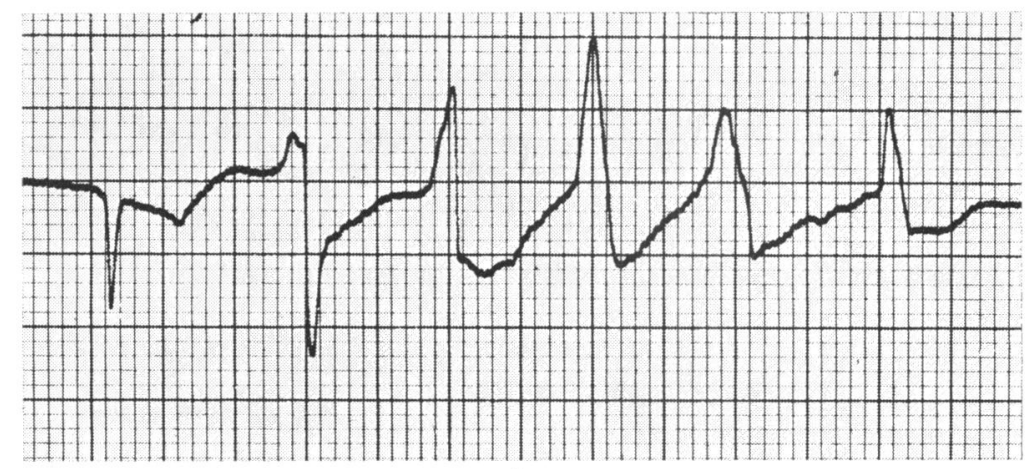

(b)

Fig. 1 (a) Ventricular tachycardia showing torsade de pointes (lead II, case 1). (b) Ventricular tachycardia showing torsade de pointes (lead V1, case 1).

Fig. 2 (a) Ventricular tachycardia showing torsade de pointes (lead II, case 4). (b) Ventricular tachycardia showing torsade de pointes (praecordial lead V1, case 4).

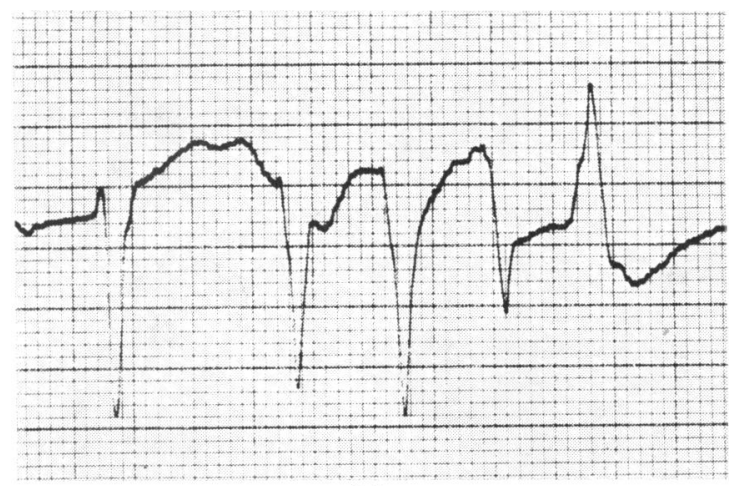

(a)

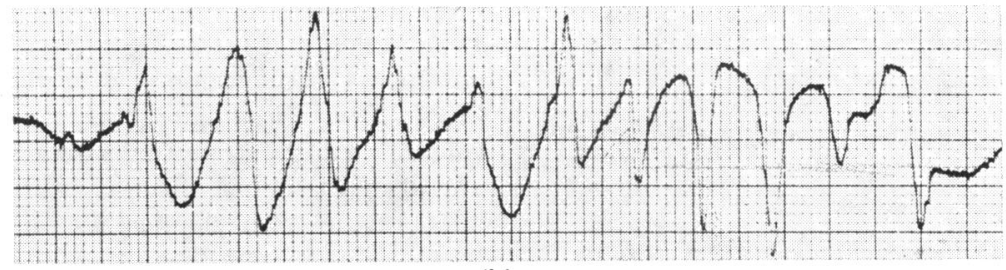

(b)

caine (Fig. 5). These four patients were treated by rapid ventricular pacing (100 pulses per minute) which proved to be effective in suppressing the ventricular arrhythmia. In view of the failure of lignocaine to control the arrhythmia and also the development of atrioventricular block in two patients, we treated the following four patients presenting to us by rapid ventricular pacing without attempting to initiate treatment with lignocaine. The arrhythmia was controlled successfully by this treatment.

The prolonged QT intervals returned to normal 


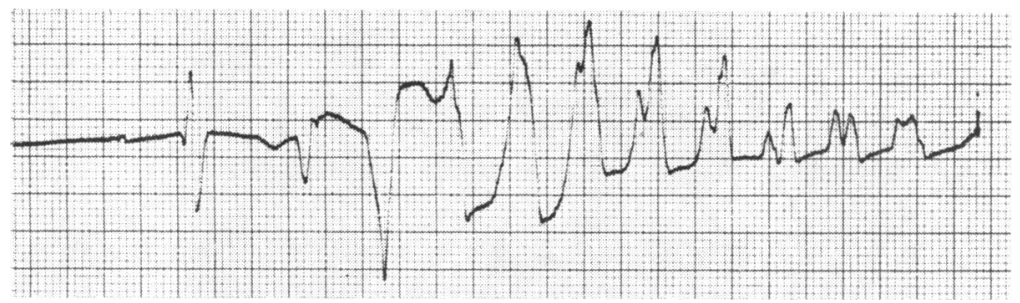

Fig. 3 Ventricular tachycardia showing torsade de pointes (praecordial lead V1, case 3).

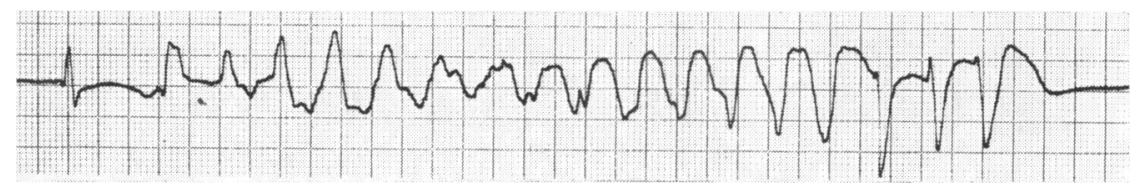

Fig. 4 Ventricular tachycardia showing torsade de pointes (monitor lead, case 8).

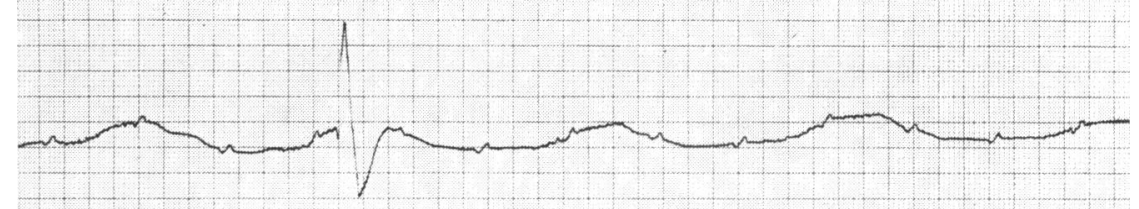

Fig. 5 Complete atrioventricular block after $100 \mathrm{mg}$ intravenous bolus of lignocaine. Thirteen $P$ waves with one ventricular escape beat (praecordial lead V1, case 3).

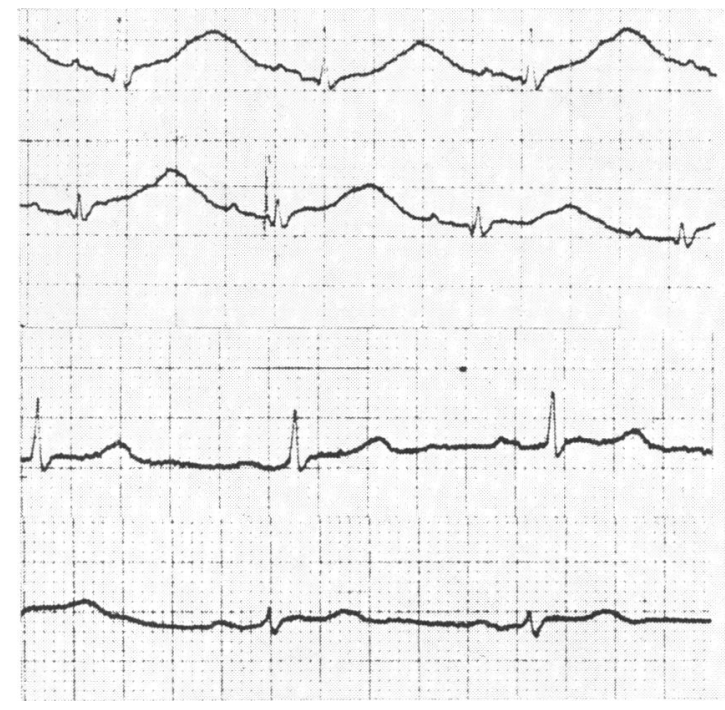

Fig. 6 Prolonged $Q T$ interval $0.64 s(Q T c=0.7)$ on admission and after a few days (lead aVL, case 8).

values in all eight patients with concomitant cessation of the ventricular arrhythmias two to four days after prenylamine was discontinued (Fig. 6).

On admission none of these patients had clinical, electrocardiographic, or enzymatic signs of myocardial ischaemia or infarction. Serum potassium, magnesium, and calcium (Table) were within the normal range of values.

In addition, all the first and second degree relatives of our patients were examined and none was found to have prolongation of the QT interval on the electrocardiogram or a history of syncope.

\section{Comment}

Much is known about the pharmacological action of prenylamine ${ }^{6}$ but the exact mechanism of its antianginal action is still uncertain. It seems probable that this is largely a result of inhibition of cathecholamine uptake by the storage granules. ${ }^{7}$ It is known that intravenous prenylamine produces coronary vasodilatation and an increase in coronary blood flow. ${ }^{8}$ Prenylamine is also known to delay calcium transport in the sarcoplasmic reticulum ${ }^{9}$ and its antianginal effect is caused in part by its effect on electromechanical coupling. It is known to have a large number of side effects including sedation, gastrointestinal symptoms, and skin reactions. ${ }^{10}$ Recently, a new complication has been described, ${ }^{2-4}$ which includes prolongation of the QT interval and ventricular tachycardia with syncopal attacks.

QT prolongation may be a result of ischaemic heart disease, ${ }^{11}$ hypokalaemia, hypocalcaemia, ${ }^{12}$ hypomagnesaemia, ${ }^{13}$ several antiarrhythmic drugs, ${ }^{14}$ 
treatment with phenothiazines ${ }^{15} 16$ and tricyclic compounds, ${ }^{16}$ liquid protein diets, ${ }^{17}$ and is a feature of the Jervell-Lange-Nielson ${ }^{18}{ }^{19}$ and the RomanoWard syndromes. ${ }^{20}{ }^{21} \mathrm{QT}$ prolongation encourages re-entry processes and ventricular arrhythmias including torsade de pointes. Torsade de pointes may also arise during slow heart rhythm as an escape mechanism in sinus node dysfunction and atrioventricular block. ${ }^{22}{ }^{23}$ It has also been reported in a neonate with myocarditis ${ }^{24}$ and as a rare complication of ventricular pacing. ${ }^{25}$

In the eight cases described above we wish to draw attention to the prolongation of the QT interval induced by prenylamine, which was followed by torsade de pointes. The effects were reversible and controlled by ventricular pacing. All eight patients were examined echocardiographically and phonocardiographically and none was found to have prolapse of the mitral valve or any cardiomyopathy detectable by these tests. In all cases the prolonged QT intervals returned to normal values within several days after withdrawal of prenylamine, with the concomitant disappearance of the ventricular arrhythmias. Neither syncope nor palpitation has recurred in any of our patients on follow-up, and none has shown conduction disorders or arrhythmias.

The occurrence of atrioventricular block after an intravenous bolus of lignocaine is of some interest. The drug normally asserts minimal effects on the cardiac conducting system, and heart block induced by lignocaine is a rare complication. ${ }^{26}$ Thus the induction of atrioventricular block in two patients of four to whom lignocaine was given is a source of some misgiving. Though unconfirmed, we cannot discount the possibility that at least in some cases lignocaine may be inadvisable in torsade de pointes.

The confident diagnosis of torsade de pointes requires the simultaneous recording of three leads; not every run of ventricular extrasystoles which change shape can be given this label. In view of the urgency of the situation we recorded only two leads (Fig. 1 and 2).

Torsade de pointes can be treated either by intravenous isoprenaline infusion or by pacing. Since the aetiology of the arrhythmia in our patients was secondary to prenylamine and there was a presumed risk of recurrence until serum levels of the drug would have fallen, we chose pacing, wishing to avoid the possible hazards of prolonged or repeated intravenous isoprenaline, especially in patients with angina.

We advise routine electrocardiographic observations in patients on prenylamine. Particular attention should be paid to the appearance of new albeit mild ventricular arrhythmias and prolonga- tion of the QT interval, which may be the harbingers of life-threatening torsade de pointes.

\section{References}

1 Tucker H, Carson P, Bass N, Massey J. Prenylamine in treatment of angina. $B r$ Heart $\mathcal{F} 1974$; 36: 1001-4.

2 Picard R, Auzepy P, Chauvin JP. Syncopes et altérations électrocardiographiques provoquées par la prénylamine. Ann Cardiol Angeio (Paris) 1971; 20: 627-30.

3 Puritz R, Henderson MA, Baker SN, Chamberlain DA. Ventricular arrhythmias caused by prenylamine. Br Med f 1977; ii: 608-9.

4 Fazzini PF, Marchi F, Pucci P. Q-T lungo, sincope e prenilamina. G Ital Cardiol 1973; 3: 233-9.

5 Fazzini PF, Marchi F, Pucci P. Ventricular tachycardia, a new iatrogenic possibility. Am Heart $\mathcal{F}$ 1975; 90: 805-6.

6 Biochemical aspects of prenylamine. Proceedings of Symposium Capri. Biochim Applicata 1967; 14, suppl 1.

7 Carlsson A, Waldeck B. On the mechanisms of action of prenylamine on tissue monamines. Biochim Applicata 1968; 14, suppl 1: 41.

8 Ito $\mathrm{Y}$, Hasegawa $\mathrm{Y}$. The effect of coronary vasodilators on the coronary circulation and the myocardial metabolism in the sclerotic heart diseases. Fpn Circ $\mathcal{F}$ 1963; 27: 164-71.

9 Schöne HH, Linder E. Die Wirkung des N-3'phenylpropyl-( $\left.2^{\prime}\right)-1,1$ diphenyl-propyl-(3)-amins auf den Stoffwechsel Von Serotonin und Noradrenalin. Arzneim Forsch 1960; 10: 583-5.

10 Stoker JB. Effect of prenylamine in angina pectoris. Br f Clin Pract 1968; 22: 384-5.

11 Schamroth L. Introduction to electrocardiography. 4th ed. London: Blackwell Scientific Publications, $1971: 193$.

12 Friedberg CK. Diseases of the heart. 3rd ed. London: Saunders, 1966: 1660.

13 Loeb HA, Pietras RJ, Gunnar RM, Tobin JR Jr. Paroxysmal ventricular fibrillation in two patients with hypomagnesemia: treatment by transvenous pacing. Circulation 1968; 37: 210-5.

14 Goodman LS, Gilman A. The pharmacological basis of therapeutics. 5th ed. New York: Macmillan, 1975: 683-91.

15 Shoonmaker FW, Osteen RT, Greenfield JC Jr. Thioridazine (Mellaril) induced ventricular tachycardia controlled with an artificial pacemaker. Ann Intern Med 1966; 65: 1076-8.

16 Fowler NO. McCall D, Chou TC, Holmes JC, Hanenson IB. Electrocardiographic changes and cardiac arrhythmias in patients receiving psychotropic drugs. Am $\mathcal{f}$ Cardiol 1967; 37: 223-30.

17 Singh BN, Gaarder TD, Kanegae T, Goldstein M, Montgomerie JZ, Mills $\mathrm{H}$. Liquid protein diets and Torsade de Pointes. FAMA 1978; 240: 115-9.

18 Jervell A, Lange-Nielsen F. Congenital deaf-mutism 
functional heart disease with prolongation of the Q-T interval and sudden death. Am Heart $\mathcal{F}$ 1957; 54: 59-68.

19 Levine SA, Woodworth CR. Congenital deafmutism, prolonged QT interval, syncopal attacks and sudden death. $N$ Engl f Med 1958; 259: 412-7.

20 Romano C, Gemme G, Pongigilione R. Aritimie cardiache rare dell'eta' pediatrica. II. Accessi sincopali per fibrillazione ventricolare parossistica (presentazione del primo caso della letteratura pediatrica Italiana). Clin Pediatr Bologna 1963; 45: 656-83.

21 Ward OC. A new familial cardiac syndrome in children. F Ir Med Assoc 1964; 54: 103-6.

22 Han J, Millet D, Chizzonitti B, Moe GK. Temporal dispersion of recovery of excitability in atrium and ventricle as a function of heart rate. Am Heart $\mathcal{F}$ 1966; 71: 481-7.
23 Chiche $P$, Haiat $R$, Steff $P$. Angina pectoris with syncope due to paroxysmal atrioventricular block: role of ischaemia. Report of two cases. Br Heart $\mathcal{F}$ 1974; 36: 577-81.

24 Finley JP, Radford DJ, Freedom RM. Torsade de pointes ventricular tachycardia in a newborn infant. Br Heart f 1978; 40: 421-4.

25 Evans TR, Curry PVL, Fitchett DH, Krikler DM. "Torsade de Pointes" initiated by electrical ventricular stimulation. $\mathcal{F}$ Electrocardiol 1976; 9: 255-8.

26 Gupta PK, Lichstein E, Chadda KD. Lidocaineinduced heart block in patients with bundle-branch block. Am f Cardiol 1974; 33: 487-92.

Requests for reprints to Dr A Palant, Depart ment of Cardiology, Lady Davis Carmel Hospital, POB 7222, Haifa, Israel. 